\title{
Simulation of thermal behavior of a lithium-ion battery
}

\author{
Fen Zhu*, Heng Yan, Liangde Liu, Xiangyun Liu** \\ School of material and energy, Guangdong University of technology, Guanghzou, China \\ Corresponding Author: ‘416546497@qq.com, **forlxy@163.com
}

Keywords:Lithium-ion battery Thermal simulation discharge rate convection heat transfer Abstract. A three-dimensional thermal model has been developed to examine the thermal behavior of a lithium-ion battery (LIB) during discharge. The effect of discharge rate and forced convection on the heat dissipation performance of models under different working conditions was analyzed. Simulation results show that with the battery discharge increasing from $3 \mathrm{C}$ to $7.5 \mathrm{C}$, battery temperature increases from $307.12 \mathrm{~K}$ to $338.86 \mathrm{~K}$, and the temperature difference of maximum and minimum is increases from $0.12 \mathrm{~K}$ to $1.41 \mathrm{~K}$, respectively. Rather, with the convection heat transfer coefficient increasing from $5 \mathrm{~W} /\left(\mathrm{m}^{2} \cdot \mathrm{K}\right)$ to $50 \mathrm{~W} /\left(\mathrm{m}^{2} \cdot \mathrm{K}\right)$, the battery temperature reduces $21.78 \mathrm{~K}$. So increase discharge rate increases the battery temperature and reduces temperature distribution uniformity. Enhance convection heat transfer can greatly reduce the battery temperature, but it also decrease temperature distribution uniformity.

\section{Introduction}

The lithium-ion battery with its high power density, low self-discharge rate and wide range of its application is a preferred candidate as an energy storage device for electric vehicles (EVs) and hybrid electric vehicles (HEVs). However, as a chemical power source, there are complex electrochemical reaction and material transfer during its charge and discharge. The thermal resistance is affected by these reactions and other factors such as the operating conditions and batteries arrangement, which may reduce the charging efficiency and cause the thermal runaway. Thermal manage for the LIB becomes bottlenecks in HEV and EV applications. Thermal modeling is a predominant way to research variables of operating temperature and control the temperature uniformity of LIBs within a suitable range.

From the 1980s, there have been studies of the thermal modeling of lithium-ion battery thermal modeling. In initial, the lithium-ion battery is assumed to be a uniform source of heat so as to analyze the average battery temperature. Pals and Newman ${ }^{[1]}$ developed two one-dimensional models to predict the temperature profiles in a single battery and batteries stacks. Chen and Evans 
[2-4] established two-dimensional and three-dimensional thermal models to study the thermal performance when lithium polymer batteries (LPBs) and LIBs under different charge and discharge rate. With further research, National renewable energy laboratory ${ }^{[5]}$ studied a multi-scale and multi-dimensional model combined with the internal multi-physical factors of the battery which based on the porous electrode model of $\mathrm{LIB}^{[6]}$. However, the study of thermal behavior is focused on different charge and discharge conditions, other condition of thermal management are less researched. In this paper, a three-dimensional thermal model for lithium ion battery was presented based on the finite element analysis software to study the thermal behaviors of LIB under different air-cooling conditions. The effect of discharge rate, air free cooling and air forced convection cooling on the heat dissipation performance of LIB was specific analyzed, which provide reliable reference for the design of thermal management system.

\section{Model description}

\section{Lithium-ion battery}

The LIB is composed of anode, cathode and separator. A typical LIB uses $\mathrm{LiCoO}_{2} / \mathrm{C}$ for cathode/anode materials. The electrochemical reactions during the charge and discharge have the expression as:

At positive electrode:

$$
\mathrm{Li}_{\mathrm{x}} \mathrm{C}_{6} \stackrel{\text { discharge }}{\underset{\text { charge }}{P}} \mathrm{C}_{6}+\mathrm{xLi}^{+}+\mathrm{xe}^{-}
$$

At negative electrode:

$$
\mathrm{LiC}_{6} \underset{\text { charge }}{\stackrel{\text { discharge }}{\text { harge }}} \mathrm{Li}_{1-2 \mathrm{x}} \mathrm{C}_{6}+2 \mathrm{xLi}^{+}+2 \mathrm{xe}^{-}
$$

Overall reaction for typical Li-ion battery:

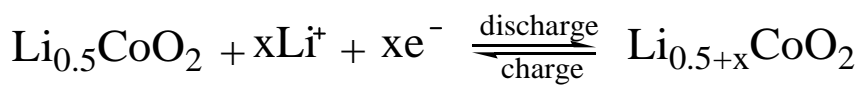

\section{Model definition}

A cylindrical 18650 lithium-ion battery comprising a $\mathrm{LiMn}_{2} \mathrm{O}_{4}$ cathode and a graphite anode during a charge-discharge cycle was simulated in this work.

The cell model is build using the LIB interface. The main components about the cell model are illustrated in Table. 1 
The thermal model is created in three-dimensional using the Conjugate Heat Transfer interface. The geometry details and properties of battery used in present study are given in Table.2. Axial symmetric heat transfer principle is employed for this simulation. The model is consists of four domains:(1)active battery material domain;(2)mandrel;(3)cylindrical battery connector;(4)flow compartment. The battery analysis in this paper is placed in a matrix of battery pack.

Table.1. Physical properties of materials.

\begin{tabular}{|l|l|l|l|l|l|}
\hline \multicolumn{1}{|c|}{ material } & \multicolumn{1}{|c|}{ material } & $\begin{array}{l}\text { Thickness } \\
(\mu \mathrm{m})\end{array}$ & $\begin{array}{l}\text { Thermal } \\
\text { conductivity } \\
(\mathrm{W} / \mathrm{m} / \mathrm{K})\end{array}$ & $\begin{array}{l}\text { Density } \\
(\mathrm{kg} / \mathrm{m} 3)\end{array}$ & $\begin{array}{l}\text { Heat } \\
(\mathrm{J} / \mathrm{kg} \mathrm{K})\end{array}$ \\
\hline Negative current collector & Aluminum & 7 & 398 & 8933 & 385 \\
\hline Negative porous electrode & $\mathrm{LixC}_{6} \mathrm{MCMB}$ & 58 & 1.04 & 1347.3 & 1437.4 \\
\hline Separator & - & 30 & 0.34 & 1000 & 1978.2 \\
\hline Positive porous electrode & $\mathrm{LiyMn} \mathrm{O}_{4}$ & 58 & 1.58 & 2328.5 & 1269.2 \\
\hline Positive current collector & $\mathrm{Cu}$ & 12 & 170 & 2770 & 875 \\
\hline
\end{tabular}

Table.2. Parameters of lithium ion battery

\begin{tabular}{|c|c|c|c|c|c|}
\hline Height & Radius & Density & Capacity & Voltage & Mass \\
\hline $65 \mathrm{~mm}$ & $9 \mathrm{~mm}$ & $2055.2 \mathrm{~kg} / \mathrm{m}^{3}$ & $2.5 \mathrm{~A} \cdot \mathrm{h}$ & $3.7 \mathrm{~V}$ & $48 \mathrm{~g}$ \\
\hline
\end{tabular}

\section{Results and discussion}

\section{Effect of discharge rate}

As Variety of discharge rate with $7.5 \mathrm{C}, 5 \mathrm{C}$ and $3 \mathrm{C}$ the performance of temperature is shown in Fig.1. It is apparently that the temperature increases greatly with the increase of the discharge rate. And the uniform of the temperature is decreased due to the temperature difference between the highest and the lowest is gradually widened the gap with the increase of discharge rate.

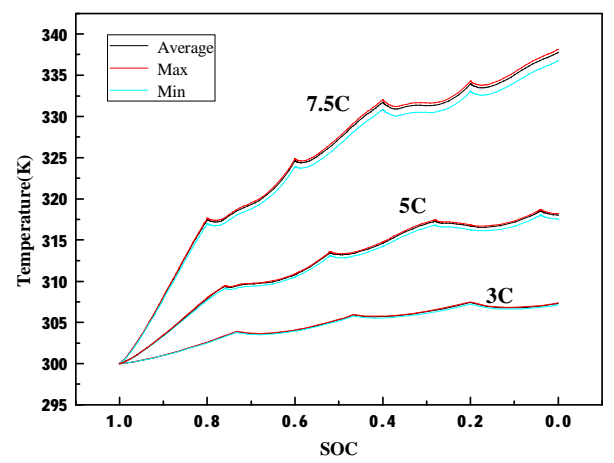

Fig.1 Maximum temperature, minimum temperature, discharge rate and average temperature under 7.5C, 5C, and $3 \mathrm{C}$

The simulation results of the temperature distribution are show in Fig.2. By observing the 3D 
diagram, the temperature is more obvious as the discharge rate increases. The maximum temperature appears at the active battery material towards the bottom of the battery which is thermally isolated. This is because the electrochemical reaction makes internal heat generation rate of the battery is very high, and the external convection is relatively small, the heat generation rate of the battery is much greater than the heat dissipation rate, the heat accumulates continuously, making the temperature rising fast.

All these indicate that the temperature would become very high and the temperature exhibition would become more non-uniform when the battery under higher discharge rate. So, battery thermal management is particularly important when it is subjected to high-rate discharge.

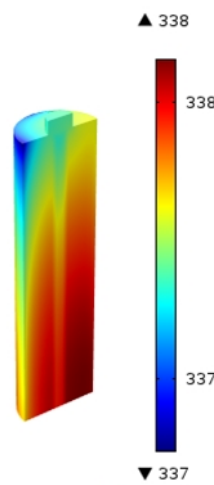

(a)

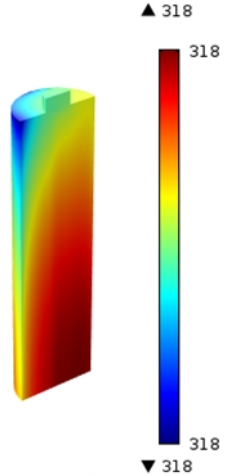

(b)

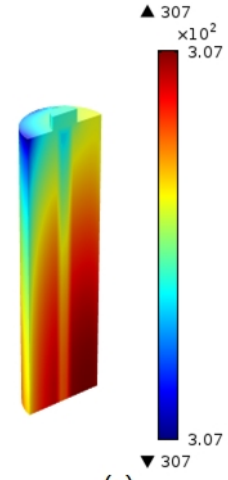

(c)

Fig.2. Temperature distribution of battery module under different discharge rates :(a)7.5C; (b)5C; (c)3C

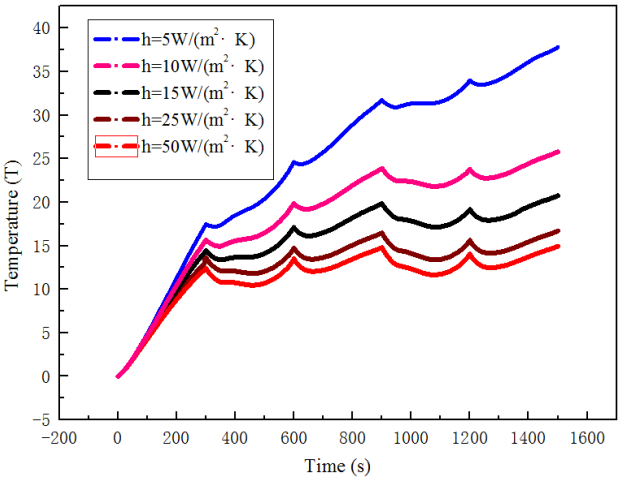

Fig.3 Temperature variation under 7.5C discharge rate on different convection conditions

\section{Effect of forced convection on heat transfer}

The average temperature variation between initial and after 1500 s discharge under $7.5 \mathrm{C}$ discharge rate with the different convective heat transfer coefficient is exhibit in Fig.3. The typical values of 5, $10,15,25$ and $50 \mathrm{~W} /\left(\mathrm{m}^{2} \cdot \mathrm{K}\right){ }^{[7]}$ were employed to analyze the influence of heat transfer coefficient in the thermal behavior. From the figure. 3 can know that enhancing the forced convection can significantly depresses the temperature of LIB. The higher heat transfer coefficient is, the lower temperature is. However the suppression of temperature increase is weakened as the forced convection enhanced. The heat transfer coefficient in the internal battery is very low is the main reason for this phenomenon. And the convective heat transfer coefficient is closely related to the power of the cooling fan in the battery module. Larger convective heat transfer coefficient will inevitably require cooling fan with greater power, resulting in excess battery module energy consumption. 


\section{Conclusions}

1) Increasing the discharge rate of the battery will rise the battery temperature. And the temperature distribution becomes uneven as the elevation of discharge rate at the same time. When the discharge rate is $7.5 \mathrm{C}$, the maximum temperature of batter is $338.86 \mathrm{~K}$ and the temperature difference of maximum and minimum is $1.41 \mathrm{~K}$.

2) Enhance convection heat transfer can markedly decrease the temperature of the battery. Meanwhile, the temperature is reduced but the temperature uniformity is decreased as the coefficient increased. The maximum temperature is $338.14 \mathrm{~K}$ and $316.36 \mathrm{~K}$, and the difference of the maximum temperature and minimum temperature is $1.36 \mathrm{~K}, 1.84 \mathrm{~K}$ when the heat transfer coefficient is $5 \mathrm{~W} /\left(\mathrm{m}^{2} \cdot \mathrm{K}\right)$ and $50 \mathrm{~W} /\left(\mathrm{m}^{2} \cdot \mathrm{K}\right)$, respectively. Rather, the simulation results indicate that the temperature difference does not expend infinitely when the heat transfer enhancement to a certain extent. There are only $0.07 \mathrm{~K}$ distance between heat transfer coefficient is $25 \mathrm{~W} /\left(\mathrm{m}^{2} \cdot \mathrm{K}\right)$ and $50 \mathrm{~W} /\left(\mathrm{m}^{2} \cdot \mathrm{K}\right)$.

3) From the figure analyzed above, there are some temperature steps during the operation. This issue needs further discussion and research.

\section{Literature References}

[1]Pals C R, Newman J. Journal of the Electrochemical Society, 1995, 142(10): 3274-3281.

[2-4]Chen Y, Evans J W. Journal of the Electrochemical Society, 1993, 140(7): 1833-1838.

[5] Kim G H, Smith K, Lee K J, et al. Journal of The Electrochemical Society, 2011, 158(8): A955-A969.

[6] Doyle M, Newman J, Gozdz A S, et al. Journal of the Electrochemical Society, 1996, 143(6): 1890-1903.

[7] Jun Cheng, Xun Li, Ming Jia. The Chinese Journal of Nonferrous Metals, 2015, 25(6): $1607-1616$ 